\title{
PREDIKSI PERTUMBUHAN PERBANKAN SYARIAH DI INDONESIA TAHUN 2022
}

\author{
Rudy Widodo ${ }^{1}$, Galih Adhidharma ${ }^{2}$ \& M. Arna Ramadhan ${ }^{3}$ \\ $1 \& 2$ Otoritas Jasa Keuangan \\ ${ }^{3}$ Buka Data Indonesia \\ Email:rudy.w@ojk.go.id,galih.adhidharma@ojk.go.id,arnaramadhan31@gmail.com
}

\begin{abstract}
ABSTRAK
Penelitian ini bertujuan untuk memprediksi pertumbuhan perbankan syariah tahun 2022 di Indonesia yang dilihat dari aspek aset, pembiayaan, dan dana pihak ketiga. Data yang digunakan pada penelitian ini yaitu data aset, pembiayaan, dan dana pihak ketiga perbankan syariah periode Januari 2011 sampai dengan September 2021. Variabel penyerta yang digunakan untuk memprediksi pertumbuhan perbankan syariah adalah Return on Asset (ROA), Not Perfoming Financing (NPF), inflasi, BI rate, Indesk Harga Saham Gabungan (IHSG), dan Gross Domestic Product (GDP). Analisis data menggunakan metode forecasting ARIMA (Autoregressive Integrated Moving Average), ARIMAX (Autoregressive Integrated Moving Average with Explanatory Variables), dan VAR (Vector Autoregressive). Hasil penelitian menunjukkan bahwa aset, pembiayaan, dan dana pihak ketiga perbankan syariah tahun 2022 tetap akan mengalami pertumbuhan yang positif dimana besaran aset perbankan syariah diprediksi mencapai 694 hingga 734 triliun rupiah. Pertumbuhan pembiayaan mencapai 452 hingga 470 triliun rupiah dan pertumbuhan dana pihak ketiga mencapai 549 sampai dengan 575 triliun rupiah.
\end{abstract}

Kata Kunci: Perbankan Syariah, Asset, Pembiayaan, Dana Pihak Ketiga, Forecasting.

\begin{abstract}
This study aims to predict the growth of Islamic banking in 2022 in Indonesia in terms of assets, financing, and third party funds. The data used in this study are data on assets, financing, and third party funds of Islamic banking for the period January 2011 - September 2021. The external variables used to predict the growth of Islamic banking are ROA, NPF, inflation, BI rate, IHSG, and GDP. Data analysis used forecasting methods ARIMA (Autoregressive Integrated Moving Average), ARIMAX (Autoregressive Integrated Moving Average with Explanatory Variables), and VAR (Vector Autoregressive). The results show that the assets, financing, and third party funds of Islamic banking in 2022 will continue to experience positive growth where the amount of Islamic banking assets is predicted to reach 694 to 734 trillion rupiah. Financing growth reached 452 to 470 trillion rupiah and growth in third party funds reached 549 to 575 trillion rupiah.
\end{abstract}

Keywords: Islamic Banking, Assets, Financing, Third Party Funds, Forecasting. 


\section{PENDAHULUAN}

Peramalan dalam dunia ekonomi, termasuk makroekonomi, perbankan dan pasar keuangan, merupakan salah satu faktor penting dalam pengambilan keputusan. Kebijakan yang akan diimplementasikan oleh otoritas perlu mempertimbangkan analisis kondisi masa depan (forward-looking) maka prediksi yang akurat menjadi penting untuk dilakukan, baik pada level makroekonomi Negara (Boneva et al, 2018), siklus bisnis (Osborn \& Sensier, 2002), volatilitas pasar keuangan (Zhang, Ma, \& Liao, 2020), maupun keterhubungan variabel keuangan dengan forecasting makroekonomi (Chen \& Ranciere, 2016). Dalam konteks ini, prediksi mengenai kondisi perbankan syariah sebagai bagian dari industri perbankan dan keuangan mendapatkan relevansinya.

Peramalan mengenai pertumbuhan perbankan syariah sudah pernah dilakukan namun masih terbatas pada aspek tertentu, misalnya asset. Dalam studinya, Sukmana \& Kuswanto (2015) mencoba melakukan proyeksi asset share perbankan syariah Indonesia yang kemudian diperbandingkan dengan proyeksi yang dilakukan oleh otoritas. Model dan hasil peramalan menghasilkan alternatif kuantifikasi proyeksi aset perbankan syariah. Terbatasnya penelitian terdahulu dan perlunya melakukan forecasting secara berkala untuk menganalisis kondisi perbankan syariah ke depan merupakan motivasi utama dalam analisis perbankan syariah di tahun depan.

Selain itu, hal yang perlu diperhatikan dan sangat relevan adalah konteks perekonomian yang masih berada pada masa pandemi Covid-19, dimana perekonomian di berbagai negara telah mengalami resesi akibat terbatasnya aktivitasnya ekonomi. Pada tataran nasional, Menteri Keuangan telah menyampaikan bahwa proyeksi pertumbuhan ekonomi Indonesia pada kuartal-III tahun ini akan tumbuh $4 \%$ sampai $5,7 \%$. Proyeksi pertumbuhan ekonomi Indonesia juga dilakukan dintaranya oleh International Monetary Fund (IMF) dan Organisation for Economic Co-operation and Development (OECD) yang masingmasing meramalkan bahwa ekonomi nasional akan tumbuh 3,9\% dan 5\% pada tahun 2021 . Hal ini menunjukkan bahwa dampak dari pandemi semakin terkontrol bagi perekonomian negara.

Hal tersebut di atas sejalan dengan berbagai studi yang membahas dampak pandemi terhadap perekonomian dalam sejarah dunia, antara lain analisis konsekuensi medium hingga jangka panjang dari pandemi besar dalam sejarah (Jorda et al, 2022), analisis peramalan (forecasting) dampak dari shock yang berasal Covid-19 terhadap ekonomi Mexico dengan beberapa skenario (Meza, 2020). Selain dari studi empiris, konsekuensi dari Covid-19 juga dirasakan oleh beberapa Negara ASEAN, sebagaimana terlihat dari hasil forecast beberapa lembaga internasional. Misalnya dalam Global Economic Prospects (2020), World Bank memproyeksikan pertumbuhan ekonomi yang negatif pada 2020 untuk Malaysia sebesar 4,5\%, Thailand sebesar 2,2\%, dan Philippines sebesar 4,7\%.

Kondisi ekonomi dalam masa pandemi yang sangat tidak menentu (highly uncertain) menjadi faktor yang sangat penting untuk diperhatikan dalam melakukan peramalan, termasuk peramalan akan kondisi perbankan syariah. Sumber ketidakpastian bukan berasal dari pasar keuangan, justru keadaan di pasar keuangan merefleksikan guncangan dari pancemi Covid-19. Dalam konteks ini, maka forecasting kondisi perbankan syariah perlu didudukkan dalam situasi makroekonomi yang tidak menentu dengan melihat berbagai indikator makroekonomi yang relevan. Lebih lanjut, kondisi ekonomi saat ini berkebalikan dengan asumsi yang seharusnya ada dalam teori forecasting: (1) model dapat merepresentasikan keadaan ekonomi; dan (2) forecasting harus dibangun dengan asumsi bahwa struktur ekonomi tidak mengalami perubahan (Hendry \& Clements, 2003).

Dengan adanya ketidakpastian dalam perekonomian, asumsi yang harus dibangun dalam melakukan forecasting diperlukan 
analisis terhadap berbagai skenario recovery pasca Covid-19. Skenario tersebut sangat penting untuk menjadi pertimbangan dalam analisis proyeksi perbankan syariah ke depan. Penelitian ini akan melakukan forecasting terhadap perbankan syariah di tahun 2022 mendatang.

\section{TINJAUAN PUSTAKA}

\section{Perbankan Syariah}

Bank syariah di negara-negara lain lebih dikenal sebagai bank Islam (Karim, 2011). Bank Islam didefinisikan sebagai lembaga perbankan yang melakukan semua kegiatan perbankan termasuk di dalamnya adalah pinjaman dan pembiayaan tanpa bunga (Hassine dan Limani, 2014).

Salah satu fitur yang paling membedakan bank Islam adalah produk keuangan yang didasarkan pada larangan bunga, dengan demikian desain produk yang dimiliki bank Islam adalah dengan kemitraan dan berbagi resiko. Selain dari itu, sifat dari kontrak suatu modal dalam bentuk mudharabah, dimana salah satu pihak menyediakan modal dan pihak lain memberikan enterpreunership, dengan demikian resiko informasi yang asimetris dapat diminimalisir, karena sifat kontrak yang membagi imbalan dan risiko secara sama (Onour dan Abdalla, 2011).

Bank Islam bertujuan menyediakan jasa-jasa perbankan yang sesuai dengan prinsip-prinsip dan syariat Islam dalam sistem keuangan Islam secara menyeluruh, yang bertujuan untuk membawa manfaat kepada masyarakat dalam kepemilikan dan kesejahteraan, sehingga tidak semata-mata menciptakan keuntungan maksimum dari penggunaan modalnya (Zaher dan Hassan, 2001).

\section{METODE PENELITIAN}

Pendekatan penelitian ini adalah metode kuantitatif yaitu analisis data deret waktu (time series) dengan ekonometrika dimana Verbeek (2008) mendefinisikan bahwa ekonometrika merupakan perpaduan antara teori ekonomi dan metode statistika.
Data yang digunakan pada penelitian ini merupakan data sekunder yang diperoleh dari Statistik Perbankan Syariah (SPS) yang terdiri atas variabel utama adalah aset, Pembiayaan (PYD), Dana Pihak Ketiga (DPK), dan variabel penyerta yang meliputi Return on Asset (ROA), Non Performing Financing (NPF), inflasi, Indeks Harga Saham Gabungan (IHSG), BI rate, dan Gross Domestic Product (GDP). Data penelitian yang digunakan adalah data pada periode Januari 2011 sampai dengan September 2021.

\section{ARIMA (Autoregressive Integrated Movign Average)}

Autoregressive Integrated Movign Average (ARIMA) dikenalkan oleh Box dan Jenkins (1976) sebagai salah satu metode yang dapat membuat forecasting untuk data time series. ARIMA dapat digunakan untuk memprediksi baik dalam jangka waktu pendek maupun panjang dan mempunyai akurasi yang cukup baik (Niu et al., 2010). Suatu data yang diamati tidak stationer (trend) maka bentuk umum model untuk campuran proses $\mathrm{AR}(\mathrm{p})$ dan $\mathrm{MA}(\mathrm{q})$ dengan proses differencing sebanyak d kali atau lebih ringkas ditulis model ARIMA (p,d,q) dapat dirumuskan sebagai berikut:

$$
\phi_{p}(B)(1-B)^{d} Z_{t}=\theta_{q}(B) a_{t}
$$

$Z_{t} \quad$ : Data pengamatan pada waktu ke-t

$\phi_{p} \quad:$ Koefisien parameter AR

$\theta_{q} \quad$ : Koefisien parameter MA

$a_{t} \quad$ Nilai error

B : Operator backshift

$(1-B)^{d}$ : Differencing pada orde ke-d

Penelitian tentang keuangan dan ekonomi yang menggunakan metode ARIMA antara lain Syahputra (2016) yang melakukan forecasting terhadap perkembangan rasio likuiditas, Syarif (2020) tentang perkembangan perbankan syariah, dan Muandari (2015) yang membahas tentang forecasting aset, pembiayaan, dana 
pihak ketiga, dan laba operasional pada perbankan syariah di Indonesia.

\section{ARIMAX (Autoregressive Integrated Moving Average with Explanatory Variables)}

Autoregressive Integrated Moving Average with Explanatory Variables (ARIMAX) merupakan suatu perluasan dari ARIMA yang sangat memperhatikan variabel independen. Model ini cukup populer untuk peramalan jangka pendek karena memungkinkan untuk menggunakan dua jenis variabel yaitu variabel dependen dan variabel independen.

$$
\begin{gathered}
(1-B)^{d} \phi_{p}(B) Y_{t}=\theta_{q}(B) \varepsilon_{t}+\beta_{0}+ \\
\beta_{1} X_{1 t}+\beta_{2} X_{2 t}+\cdots+\beta_{k} X_{k t}
\end{gathered}
$$

atau dapat juga dituliskan sebagai berikut:

$$
Y_{t}=\beta_{0}+\beta_{1} X_{1 t}+\beta_{2} X_{2 t}+\cdots+\beta_{k} X_{k t}+
$$

Penelitian yang pernah menggunakan ARIMAX dalam dunia perbankan syariah yaitu Aryani et al, (2018) yang memprediksi profitabilitas perbankan syariah dan Permatasari (2015) mengenai perkiraan arus uang kartal di Bank Indonesia Surabaya.

\section{VAR (Vector Autoregressive)}

Data deret waktu (time series) yang memiliki banyak variabel (multivariat) dapat dimodelkan dengan metode VAR (vector autoregressive) yang merupakan perluasan dari model ARIMA.

Kelebihan dari model Vector Autoregressive (VAR) adalah:

1. Model Vector Autoregressive (VAR) adalah model yang sederhana dan tidak perlu membedakan mana variabel yang dependen dan independen. Semua variabel pada model VAR dapat dianggap sebagai variabel independen.

2. Cara estimasi model VAR sangat mudah yaitu dengan menggunakan OLS (ordinary least square) pada setiap persamaan secara terpisah. Secara umum, model VAR(p) dimana $p$ merupakan orde autoregressive serta peubah sebanyak $\mathrm{k}$ pada waktu ke-t dapat ditulis sebagai berikut:

$$
\begin{aligned}
& Y_{t}=\beta_{10}+\beta_{11} Y_{t-1}+\beta_{12} X_{t-1}+v_{t}^{Y} \\
& X_{t}=\beta_{20}+\beta_{21} Y_{t-1}+\beta_{22} X_{t-1}+v_{t}^{X}
\end{aligned}
$$

Diantara penelitian yang menggunakan VAR yaitu Novianto dan Hadiwidjojo (2013) dan Beik dan Aprianti (2013).

\section{Evaluasi Model}

Ketiga metode akan dievaluasi melalui dua ukuran yaitu Mean Absolute Percentage Error (MAPE) dan korelasi antara nilai aktual dan fitting:

- Mean Absolute Percentage Error (MAPE)

MAPE merupakan rata-rata persentase dari nilai absolut error. Semakin kecil nilai MAPE maka model yang dibuat akan semakin baik. MAPE dapat dihitung melalui formula sebagai berikut:

$$
M A P E=\frac{\sum \frac{\left|y_{t}-\hat{y}_{t}\right|}{y_{t}} \times 100}{n}
$$

- Korelasi

Korelasi merupakan suatu ukuran yang mendeskripsikan kekuatan hubungan dua variabel. Nilai korelasi memiliki rentang antara -1 hingga 1 . Rumus yang digunakan untuk menghitung nilai korelasi sebagai berikut:

$$
r=\frac{\operatorname{cov}\left(y_{t}, \hat{y}_{t}\right)}{\sqrt{\operatorname{var}\left(y_{t}\right) \operatorname{var}\left(\hat{y}_{t}\right)}}
$$

\section{HASIL PENELITIAN DAN PEMBAHASAN}

Aset perbankan syariah terus mengalami pertumbuhan dengan tren yang terus meningkat dari tahun 2011 hingga bulan September 2021 yang mencapai angka 646 triliun rupiah. Pertumbuhan asset perbankan syariah dapat dilihat pada gambar di bawah ini: 


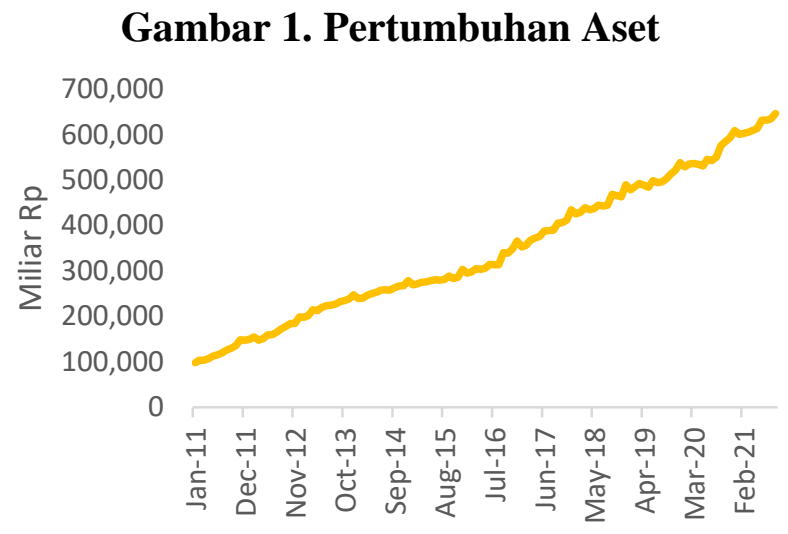

Pertumbuhan pembiayaan (PYD) tahun sejak 2011 hingga September 2021 perbankan syariah mempunyai hubungan pembiayaan (PYD) perbankan syariah telah positif yang cukup kuat dengan aset mencapai 413 triliun rupiah. perbankan syariah. Dalam kurun waktu 10

\section{Gambar 2. Pertumbuhan Pembiayaan}

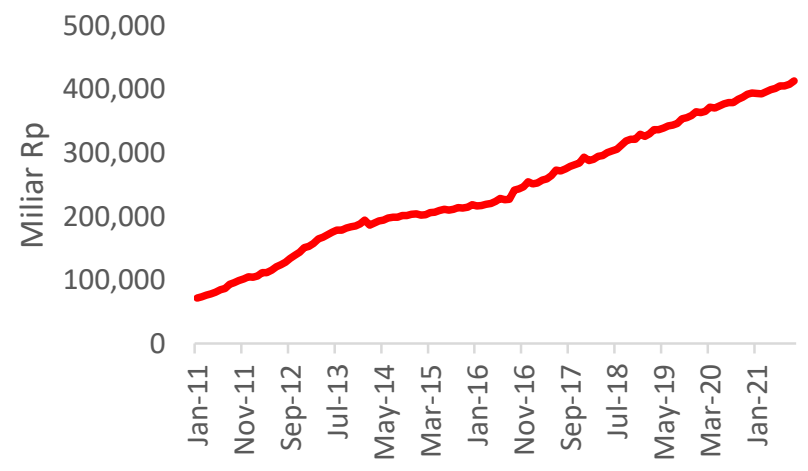

Pertumbuhaan yang signifikan juga 77 triliun rupiah, namun pada September terjadi pada dana pihak ketiga (DPK) 2021 DPK perbankan syariah telah tercatat perbankan syariah sebagaimana aset dan sebesar 503 triliun rupiah atau bertumbuh pembiayaan (PYD). Pada tahun 2011 DPK sebesar 6.5 kali dalam kurun waktu 10 tahun. perbankan syariah hanya berada pada angka

\section{Gambar 3. Pertumbuhan Dana Pihak Ketiga}

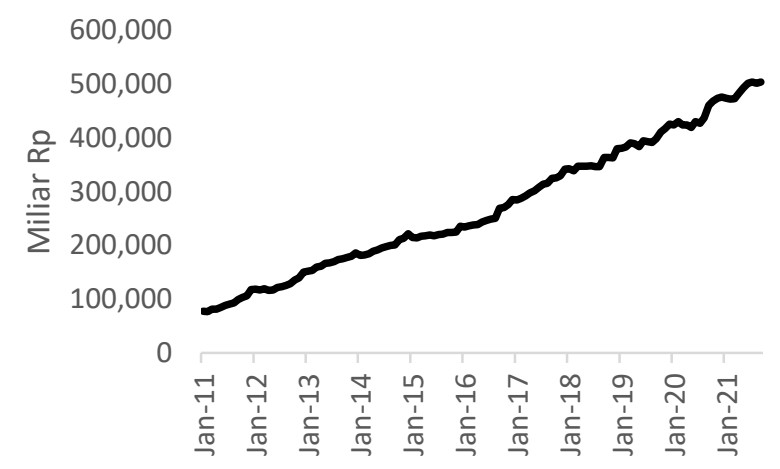

Ketiga variabel aset, pembiayaan evaluasi kebaikan prediksi dari ketiga metode (PYD), dan dana pihak ketiga (DPK) diprediksi dengan menggunakan 3 metode yaitu ARIMA, ARIMAX, dan VAR. Hasil dinilai dari Mean Absolute Percentage Error (MAPE) dan korelasi yang disajikan pada tabel berikut ini: 
Tabel 1. Evaluasi Metode Prediksi

\begin{tabular}{lcccccc}
\hline \multirow{2}{*}{ Metode } & \multicolumn{2}{c}{ ASSET } & \multicolumn{2}{c}{ PYD } & \multicolumn{2}{c}{ DPK } \\
\cline { 2 - 7 } & MAPE & r & MAPE & r & MAPE & r \\
\hline ARIMA & 1.096 & 0.99 & 0.838 & 0.99 & 1.239 & 0.99 \\
\hline ARIMAX & 0.797 & 0.99 & 1.167 & 0.99 & 1.235 & 0.99 \\
\hline VAR & 1.491 & 0.99 & 0.874 & 0.99 & 1.382 & 0.99 \\
\hline
\end{tabular}

Sumber : Data Olahan (2020)

Berdasarkan tabel evaluasi metode prediksi, diperoleh bahwa ketiga metode mempunyai performa yang cukup baik dimana nilai MAPE berkisar pada $1 \%$ yang menunjukkan rendahnya tingkat kesalahan prediksi. Nilai korelasi dari masing-masing metode ARIMA, ARIMAX, dan VAR untuk aset, pembiayaan (PYD), dan dana pihak ketiga (DPK) pun tinggi, artinya besaran hubungan antara nilai aktual dan prediksi sangat baik yang terdeskripsikan dengan nilai korelasi (r) yang lebih dari 0.9.

\section{Gambar 4. Prediksi Pertumbuhan Aset}

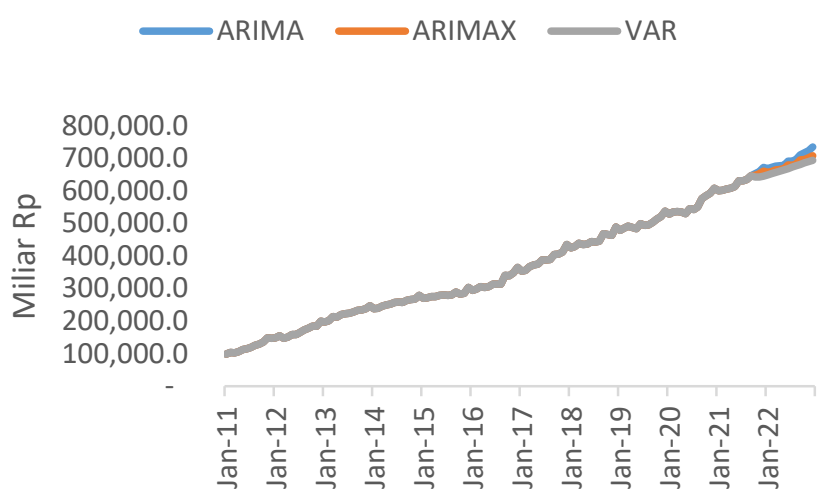

Gambar 4 merupakan grafik prediksi pertumbuhan aset perbankan syariah untuk pada tahun 2022. Pada gambar tersebut dapat dilihat bahwa aset perbankan syariah akan tetap mengalami pertumbuhan yang positif di tahun 2022. Metode ARIMA menghasilkan prediksi bahwa pertumbuhan aset akan mencapai 734 triliun rupiah, 708 triliun rupiah berdasarkan metode ARIMAX, dan 694 triliun rupiah untuk metode VAR.

Tabel 2. Prediksi Nilai Aset

\begin{tabular}{cccc}
\hline Bulan & ARIMA & ARIMAX & VAR \\
\hline Oct-21 & 653385.1 & 647511 & 642180.3 \\
\hline Nov-21 & 659378.1 & 652546.6 & 643056.3 \\
\hline Dec-21 & 672277.9 & 660908 & 645615.4 \\
\hline Jan-22 & 668353.1 & 657071.8 & 648867 \\
\hline Feb-22 & 671768.5 & 659119.2 & 652478.4 \\
\hline Mar-22 & 675773.6 & 664754.7 & 656317.1 \\
\hline Apr-22 & 677577.9 & 666151.3 & 660315.5 \\
\hline May-22 & 678520.6 & 668941.4 & 664429.9 \\
\hline Jun-22 & 691365.5 & 680234.2 & 668627.7 \\
\hline Jul-22 & 691934.2 & 678580.7 & 672883.1 \\
\hline Aug-22 & 696464.1 & 681881.1 & 677175 \\
\hline Sep-22 & 710762.7 & 694735.3 & 681486 \\
\hline Oct-22 & 717424.3 & 697118.7 & 685802 \\
\hline Nov-22 & 722839.8 & 701123.8 & 690111.7 \\
\hline
\end{tabular}


2022, Jurnal Tabarru' : Islamic Banking and Finance 5 (1) : 53 - 62

\begin{tabular}{cccc}
\hline Dec-22 & 734316.4 & 708622.9 & 694405.8 \\
\hline \multicolumn{4}{c}{ Sumber : Data Olahan (2020) }
\end{tabular}

Prediksi untuk pembiayaan (PYD) pertumbuhan yang positif di tahun 2022 perbankan syariah juga akan mengalami yang ditampilkan pada grafik berikut.

\section{Gambar 5. Prediksi Pertumbuhan Pembiayaan (PYD)}

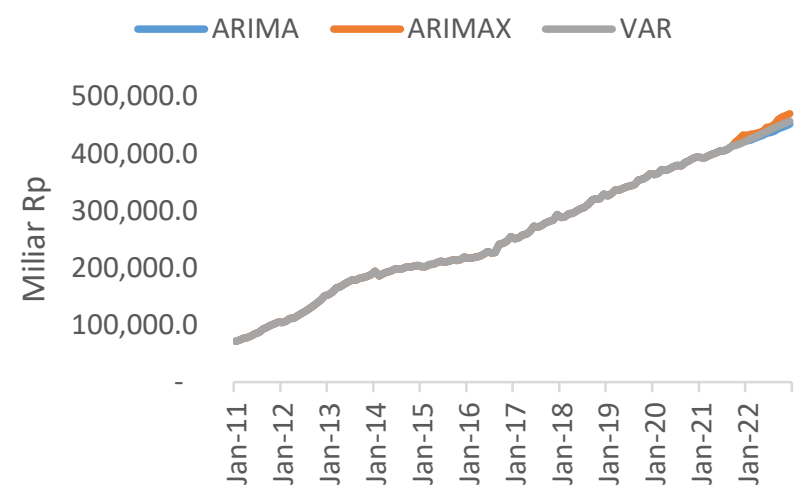

Pada tahun 2022, pembiayaan (PYD) perbankan syariah diprediksi akan tumbuh (ARIMA), 470 triliun rupiah (ARIMAX), hingga mencapai 452 triliun rupiah dan 457 triliun rupiah (VAR).

Tabel 3. Prediksi Nilai Pembiayaan (PYD)

\begin{tabular}{cccc}
\hline Bulan & ARIMA & ARIMAX & VAR \\
\hline Oct-21 & 416259.8 & 420504 & 414722.6 \\
\hline Nov-21 & 419618.8 & 426360.1 & 417223.8 \\
\hline Dec-21 & 422203.3 & 432815.2 & 420123.7 \\
\hline Jan-22 & 423071 & 432313 & 423191.3 \\
\hline Feb-22 & 424245.6 & 434183.1 & 426337.5 \\
\hline Mar-22 & 427400 & 435374.6 & 429519.9 \\
\hline Apr-22 & 430299.4 & 437277.2 & 432713.4 \\
\hline May-22 & 432434.5 & 438693.7 & 435900.8 \\
\hline Jun-22 & 435673.5 & 446047.6 & 439069.2 \\
\hline Jul-22 & 437113.3 & 447829.4 & 442209.1 \\
\hline Aug-22 & 439820.4 & 451413.3 & 445312.9 \\
\hline Sep-22 & 443675.6 & 460243.4 & 448375.1 \\
\hline Oct-22 & 446463.6 & 464652 & 451391.8 \\
\hline Nov-22 & 449442.6 & 467416.5 & 454360.1 \\
\hline Dec-22 & 452063.4 & 470559.4 & 457278.5 \\
\hline
\end{tabular}

Sumber : Data Olahan (2020)

Sejalan dengan aset dan pembiayaan (PYD), dana pihak ketiga (DPK) perbankan syariah juga akan mengalami pertumbuhan yang positif di tahun 2022. Pertumbuhan dana pihak ketiga (DPK) perbankan syariah ini diprediksi akan mencapai angka 563 triliun rupiah (ARIMA), 575 triliun rupiah (ARIMAX), dan 549 triliun rupiah (VAR). 


\section{Gambar 6. Prediksi Pertumbuhan Dana Pihak Ketiga (DPK)}

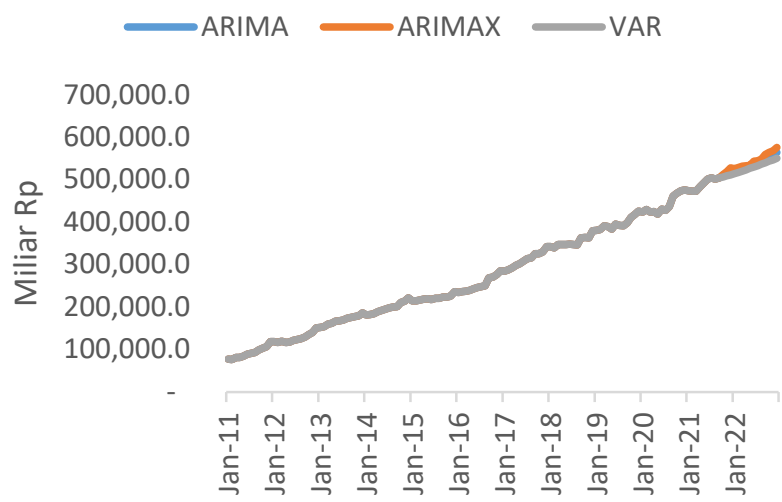

Prediksi pertumbuhan dana pihak

ketiga (DPK) yang disajikan dalam bulan

dapat dilihat pada tabel berikut ini.

Tabel 4. Prediksi Nilai Dana Pihak Ketiga (DPK)

\begin{tabular}{cccc}
\hline Bulan & ARIMA & ARIMAX & VAR \\
\hline Oct-21 & 510571.2 & 512319.9 & 506157.1 \\
\hline Nov-21 & 515337 & 518311.3 & 508659.7 \\
\hline Dec-21 & 519462.2 & 528052.6 & 511297.6 \\
\hline Jan-22 & 520066.6 & 525575.2 & 514071.9 \\
\hline Feb-22 & 522802.7 & 528173.2 & 516977.5 \\
\hline Mar-22 & 522980.1 & 531296.8 & 520002.1 \\
\hline Apr-22 & 527964.3 & 532910 & 523129 \\
\hline May-22 & 530831.4 & 533926.1 & 526340.4 \\
\hline Jun-22 & 537663 & 543469.7 & 529618.8 \\
\hline Jul-22 & 539293.5 & 544201.4 & 532948.1 \\
\hline Aug-22 & 542449.1 & 547905.4 & 536313.9 \\
\hline Sep-22 & 550458.1 & 558762.9 & 539703.6 \\
\hline Oct-22 & 555789.7 & 563881.9 & 543106.5 \\
\hline Nov-22 & 560151.7 & 567942.2 & 546513.6 \\
\hline Dec-22 & 563448.8 & 575990.3 & 549917.6 \\
\hline
\end{tabular}

Sumber : Data Olahan (2020)

Tabel 5 menyajikan pertumbuhan 2022. Pertumbuhan pembiayaan (PYD) aset, pembiayaan (PYD), dan dana pihak perbankan syariah akan mencapai angka ketiga (DPK) dalam persentase (\%, yoy). $7.1 \%$ sampai dengan $8.8 \%$ sedangkan dana Pertumbuhan aset berdasarkan ketiga metode pihak ketiga (DPK) diprediksi tumbuh ARIMA, ARIMAX, dan VAR diprediksi sebesar $7.6 \%$ hingga $9.1 \%$. sebesar $7.2 \%$ hingga $9.2 \%$ yoy di tahun

Tabel 5. Pertumbuhan Perbankan Syariah

\begin{tabular}{cccc}
\hline Metode & $\begin{array}{c}\text { Asset } \\
(\boldsymbol{\%}, \text { yoy })\end{array}$ & $\begin{array}{c}\text { PYD } \\
(\boldsymbol{\%}, \text { yoy })\end{array}$ & $\begin{array}{c}\text { DPK } \\
(\boldsymbol{\%}, \text { yoy })\end{array}$ \\
\hline ARIMA & 9.2 & 7.1 & 8.5 \\
\hline ARIMAX & 7.2 & 8.7 & 9.1 \\
\hline VAR & 7.6 & 8.8 & 7.6 \\
\hline
\end{tabular}

Sumber : Data Olahan (2020) 
2022, Jurnal Tabarru' : Islamic Banking and Finance 5 (1) : 53 - 62

Perbankan syariah akan tetap mengalami pertumbuhan yang signifikan pada tahun 2022 mendatang. Perekonomian Indonesia yang sudah mulai kembali pulih turut mendorong tumbuhnya perbankan syariah, baik dari aset, pembiayaan (PYD), dan dana pihak ketiga (DPK).

Ketiga metode menunjukkan pertumbuhan positif bagi ketiga variabel aset, pembiayaan, dan dana pihak ketiga. Pertumbuhan dana pihak ketiga cenderung lebih tinggi dibandingkan dengan pertumbuhan aset dan pembiayaan.

\section{KESIMPULAN}

Perbankan syariah di Indonesia akan terus mengalami pertumbuhan yang positif pada tahun 2022 dimana aset akan dapat mencapai angka 694-734 triliun rupiah, pembiayaan (PYD) yang mencapai angka 452-470 triliun rupiah, dan dana pihak ketiga (DPK) yang diprediksi mencapai 549-575 triliun rupiah. Hal ini menunjukkan bahwa masyarakat Indonesia memberikan kepercayaan yang terus meningkat kepada perbankan syariah. Di samping itu, pertumbuhan perbankan syariah yang positif juga mengindikasikan bahwa perputaran roda ekonomi Indonesia yang sudah mulai pulih pasca pandemi Covid-19.

\section{DAFTAR PUSTAKA}

Aryani, Sri., Aidi, Muhammad Nur., \& Syafitri, Utami Dyah. 2018. Analysis of The Profitability of Islamic Banking Using Arimax Model and Regression with Arima Error Model. International Journal of Scientific Research in Science, Engineering and Technology, 4(8), p. 49-53.

Beik, Irfan Sqauqy., \& Aprianti, Winda Nur. 2013. Analisis Faktor-Faktor yang Mempengaruhi Pembiayaan Bank Syariah Untuk Sektor Pertanian di Indonesia. Jurnal Agro Ekonomi, 31(1), p. 19-36.

Boneva, Lena., de Roure, Calebe., \& Morley, Ben. 2018. The Impact of The Bank of England's Corporate Bond Purchase Scheme on Yields Spreads.
Bank of England Staff Working Paper No. 719, p. 1-13.

Box, George., and Jenkins, Gwilym. 1976. Time Series Analysis: Forecasting and Control. Holden-Day. San Fransisco.

Chen, Sophia., \& Ranciere, Romain. 2016. Financial Information and Macroeconomic Forecasts. IMF Working Paper No. 16/251, p. 1-10.

Hassine, Mustapha Ben., \& Limani, Ratiba. 2014. The Impact of Bank Characteristics on the Efficiency: Evidence from MENA Islamic Banks. Journal of Applied Finance and Banking, 4(3), p. 237-253.

Hendry, David F., and Clements, Michael P. 2003. Economic Forecasting: Some Lessons from Recent Research. Economic Modelling, 20(2), p. 301329

Jorda, Oscar., Singh, Sanjay R., \& Taylor, Alan M. 2022. Longer-Run Economic Consequences of Pandemics. The Review of Economics and Statistics, 104(1), p. 166-175.

Karim, Adiwarman A. 2011. Bank Islam: Analisis Fiqih dan Keuangan. Rajawali Pers. Jakarta.

Meza, Felipe. 2020. Forecasting the Impact of the COVID-19 Shock on the Mexican Economy. ITAM Centro Interdisciplinario COVID-19, p. 210225.

Muandari, Ira Reszita. 2015. Prediksi Perkembangan Aset, Dana Pihak Ketiga, Pembiayaan, dan Laba Operasional Perbankan Syariah dengan Metode ARIMA. Skripsi. Sekolah Tinggi Ilmu Ekonomi Perbanas Surabaya.

Niu, Dong-Xiao., Lu, Jian-Chang., and Jia, Zheng-Yuan. 2004. A study of shortterm load forecasting based on ARIMA-ANN. Proceeding of 2004 International Conference on Machine Learning and Cybernetics (IEEE Cat No. 04EX826). 
2022, Jurnal Tabarru' : Islamic Banking and Finance 5 (1) : 53 - 62

Novianto, Abdullah Syakur. dan Hadwidjojo, Djumilah. 2013. Analisis Faktor-faktor yang Mempengaruhi Penghimpunan Deposito Mudharabah Perbankan Syariah di Indonesia. Jurnal Aplikasi Manajemen, 2(4), p. 595-604.

Onour, Ibrahim., \& Abdalla, Abdelgadir. 2011. Scale and Technical Efficiency of Islamic Banks in Sudan: Data Envelopment Analysis. MPRA Paper No. 29885, p. 1-20.

Osborn, Denise R., \& Sensier, Marianne. 2002. The Prediction of Business Cycle Phases: Financial Variables and International Linkages. National Institute Economic Review, 182(1), p. 96-105.

Permatasari, Ratna Achdiati. 2015. Pemodelan Regresi Time Series dan ARIMAX dengan Variasi Kalender untuk Perkiraan Arus Uang Kartal di Bank Indonesia Surabaya. Skripsi. Institut Teknologi Sepuluh Nopember.

Sukmana, Raditya., \& Kuswanto, Heri. 2015. Assessment on The Islamic Banking Market Share Projection by Bank Indonesia and Proposed Methods. Journal of Islamic Monetary Economics and Finance, 1(1), p. 107-133.

Syahputra, Choirul Takdir. 2016. Peramalan Perkembangan Rasio Likuiditas PT. Bank Syariah Mandiri dengan Menggunakan Metode ARIMA BoxJenkins. Diploma Thesis. Institut Teknologi Sepuluh Nopember.

Syarif, Ahmad. 2020. Forecasting The Development of Islamic Banks in Indonesia: Adopting ARIMA Model. JTAM (Jurnal Teori dan Aplikasi Matematika), 4(2), p. 190-203.

Verbeek, Marno. 2008. Guide to Modern Econometrics, Third Edition. John Wiley and Sons. England.

Zaher, Tarek S., \& Hasan, M. Kabir. 2001. A Comparative Literature Survey of
Islamic Finance and Banking. Financial Markets Institutions and Finance, 10(4), p. 155-199.

Zhang, Yaojie., Ma, Feng., and Liao, Yin. 2020. Forecasting global equity market volatilities. International Journal of Forecasting Elsevier, 36(4), p. 1306-1307. 